\title{
Evaluation of Tourism Development Potential and High-quality Development Countermeasures in Shandong Section of the Yellow River Basin
}

\author{
Yu Jie ${ }^{1}$, Liu Yanan ${ }^{1, *}$ \\ ${ }^{1}$ Business School, Shandong Normal University, Ji'nan 250300, China
}

\begin{abstract}
As a major national strategy, ecological protection and high-quality development of the Yellow River Basin aims to promote high-quality development in the areas of economy, ecology, society, people's livelihood, and tourism. Taking 9 cities in the Shandong section of the Yellow River Basin as the main research area, the entropy Topsis method is used to analyze and evaluate the tourism development potential. The evaluation index system is constructed from the four subsystems of tourism economic potential, tourism service potential, tourism protection potential, and tourism environmental potential. The results of the study found that the comprehensive score of tourism development potential of the study area is between 0.2734 and 0.7054 , with Ji'nan having the highest comprehensive score. At the same time, there is an imbalance in the development level of various subsystems within the region. On this basis, high-quality development countermeasures are proposed for the tourism development.
\end{abstract}

\section{Introduction}

On September 18, 2019, ecological protection and highquality development of the Yellow River Basin will become a major international strategy [1]. It aims to promote the Yellow River Basin ecological and economic development of high quality as the fundamental focus, while involving society, people's livelihood, education, tourism and other implications. Promoting the highquality development of tourism is one of the important contents. Shandong Province is located in the lower reaches of the Yellow River, which is the last province of the Yellow River. The Yellow River enters Shandong Province from the southwest, flows through Heze, Jining, Tai'an, Liaocheng, Dezhou, Ji'nan, Zibo, Binzhou and Dongying, and finally flows into Bohai Sea in Kenli District of Dongying City.

Tourism development potential refers to the potential ability that the existing tourism resources gradually accumulate under the influence of various environmental factors, which can become the support and guarantee of the tourism competitiveness and development and determine the tourism sustainable development in the future [2]. Kelly, Roki, Taylor and Erdem [3-6] respectively studied the tourism development potential and its influencing factors in Jordan, the Great Lakes basin, Zambia and bursa. Cao Xinxiang, Weng Gangmin, Wang Guanxiao and Shi Dan [7-10] respectively used different research methods to build tourism development potential evaluation system from different systems and perspectives, and quantitatively evaluated the tourism development potential of different research areas. It can be seen that many scholars have conducted a full study on tourism development potential related fields. Under the background of the high-quality development of the Yellow River Basin, this paper takes the nine cities that the Yellow River flows through as the main research objects, evaluates and analyzes the tourism development potential of the study area, and puts forward some countermeasures for the high-quality development of tourism on this basis. It is of great significance to promote the high-quality development of tourism in Shandong section of the Yellow River Basin.

\section{Evaluation system and model}

\subsection{Index selection and evaluation system construction}

The tourism development potential of a certain region is affected by many factors such as economy, culture and environment. Based on the connotation of tourism development potential and the characteristics of tourism, following the construction principles of scientificity, hierarchy, comprehensiveness and data operability, combined with the actual situation of the Shandong section of the Yellow River Basin, and on the basis of referring to and summarizing the previous research results [11-13], the Yellow River flow is constructed, which is composed of three levels: target level, criterion level and index level. The evaluation system of tourism development potential in Shandong Province mainly covers four subsystems of tourism economic potential, 
tourism service potential, tourism guarantee potential and tourism environment potential, as well as 21 specific evaluation indexes, as shown in Table 1.

\subsection{Model selection}

Based on the actual situation and the operability of the data, this paper chooses the Entropy TOPSIS method as the research method to study the tourism development potential of the Shandong section of the Yellow River Basin. Entropy weight method is an objective weighting method to determine the index weight by the change of index data [14]. TOPSIS method, also known as the ranking method of approaching ideal solution, calculates the relative closeness between each scheme and ideal solution by determining the distance between each evaluation object and the optimal solution and the worst solution, so as to rank the advantages and disadvantages of the schemes [15]. The entropy weight TOPSIS method is actually an improvement of the traditional TOPSIS method, and the specific steps will not be repeated here.

\subsection{Evaluation objects and data sources}

Taking nine cities along the Shandong section of the Yellow River Basin as the main evaluation objects, this paper selects the indicator data of 2019 to study the tourism development potential. The required data mainly come from the statistical yearbook of Shandong Province (2020), Shandong tourism statistics summary (2020), the national economic and social development communique of Shandong Province in 2019, etc.

\section{Evaluation of tourism development potential in Shandong section of the Yellow River Basin}

\subsection{Empirical calculation}

\subsubsection{Determination of index weight}

The index weight of the evaluation system is obtained from original data by the entropy weight method, as shown in Table 1.

Table1. Evaluation index system and weight

\begin{tabular}{|c|c|c|c|c|}
\hline Target layer & Criterion layer & Index layer & Index attribute & Weight \\
\hline \multirow{21}{*}{$\begin{array}{l}\text { A- } \\
\text { Evaluation of } \\
\text { tourism } \\
\text { development } \\
\text { potential in } \\
\text { Shandong } \\
\text { section of the } \\
\text { Yellow River } \\
\text { Basin }\end{array}$} & \multirow{6}{*}{$\begin{array}{c}\mathrm{B}_{1} \text {-Tourism } \\
\text { economic } \\
\text { potential }\end{array}$} & $\mathrm{C}_{1}$-domestic tourists & + & 0.0476 \\
\hline & & $\mathrm{C}_{2}$-number of inbound tourists & + & 0.0444 \\
\hline & & $\mathrm{C}_{3}$-domestic tourism revenue & + & 0.0457 \\
\hline & & $\mathrm{C}_{4}$-tourism foreign exchange income & + & 0.0454 \\
\hline & & $\mathrm{C}_{5}$-proportion of total tourism revenue in the tertiary industry & + & 0.0453 \\
\hline & & $\mathrm{C}_{6}$-per capita consumption level of tourists & + & 0.0520 \\
\hline & \multirow{6}{*}{$\begin{array}{c}\mathrm{B}_{2} \text {-Tourism } \\
\text { service potential }\end{array}$} & $\mathrm{C}_{7}$-Number of A-level scenic spots & + & 0.0507 \\
\hline & & $\mathrm{C}_{8}$-number of tourist resorts & + & 0.0488 \\
\hline & & $\mathrm{C}_{9}$-number of Museums & + & 0.0480 \\
\hline & & $\mathrm{C}_{10}$-Intangible Cultural Heritage & + & 0.0363 \\
\hline & & $\mathrm{C}_{11}$-number of travel agencies & + & 0.0490 \\
\hline & & $\mathrm{C}_{12}$-Number of star hotels & + & 0.0492 \\
\hline & \multirow{4}{*}{$\begin{array}{c}\mathrm{B}_{3} \text {-Tourism } \\
\text { guarantee } \\
\text { potential }\end{array}$} & $\mathrm{C}_{13}$-GDP per capita & + & 0.0469 \\
\hline & & $\mathrm{C}_{14}$-proportion of output value of tertiary industry in GDP & + & 0.0519 \\
\hline & & $\mathrm{C}_{15}$-per capita disposable income of residents & + & 0.0496 \\
\hline & & $\mathrm{C}_{16}$-road network density & + & 0.0525 \\
\hline & \multirow{5}{*}{$\begin{array}{c}\mathrm{B}_{4} \text {-Tourism } \\
\text { environmental } \\
\text { potential }\end{array}$} & $\mathrm{C}_{17}$-forest coverage & + & 0.0517 \\
\hline & & $\mathrm{C}_{18}$-Wetland coverage & + & 0.0305 \\
\hline & & $\mathrm{C}_{19}$-wastewater discharge per unit GDP & - & 0.0511 \\
\hline & & $\mathrm{C}_{20}$-sulfur dioxide emissions per unit GDP & - & 0.0517 \\
\hline & & $\mathrm{C}_{21}$-industrial smoke (dust) emission per unit GDP & - & 0.0517 \\
\hline
\end{tabular}

\subsubsection{Calculation of tourism development potential}

According to the index weight, TOPSIS method is used to evaluate and calculate the subsystems development potential and comprehensive development potential of the study area. The evaluation results are shown in Table 2. 
Table2. Calculation results of tourism development potential

\begin{tabular}{|c|c|c|c|c|c|c|c|c|c|c|}
\hline \multirow[t]{2}{*}{ City } & \multicolumn{2}{|c|}{$\begin{array}{c}\text { Tourism economic } \\
\text { potential }\end{array}$} & \multicolumn{2}{|c|}{$\begin{array}{c}\text { Tourism service } \\
\text { potential }\end{array}$} & \multicolumn{2}{|c|}{$\begin{array}{c}\text { Tourism guarantee } \\
\text { potential }\end{array}$} & \multicolumn{2}{|c|}{$\begin{array}{c}\text { Tourism } \\
\text { environment } \\
\text { potential }\end{array}$} & \multicolumn{2}{|c|}{$\begin{array}{l}\text { Comprehensive tourism } \\
\text { development potential }\end{array}$} \\
\hline & Closeness & Rank & Closeness & Rank & Closeness & Rank & Closeness & Rank & Closeness & Rank \\
\hline Heze & 0.1771 & 7 & 0.1477 & 9 & 0.4110 & 8 & 0.4213 & 6 & 0.3028 & 7 \\
\hline Jining & 0.5783 & 3 & 0.7285 & 1 & 0.4086 & 9 & 0.5772 & 4 & 0.5823 & 2 \\
\hline Tai'an & 0.6597 & 2 & 0.5727 & 3 & 0.4809 & 3 & 0.5973 & 3 & 0.5804 & 3 \\
\hline Liaocheng & 0.1429 & 8 & 0.1531 & 8 & 0.4542 & 5 & 0.5000 & 5 & 0.3430 & 6 \\
\hline Dezhou & 0.0731 & 9 & 0.1735 & 7 & 0.4193 & 7 & 0.3472 & 8 & 0.2734 & 9 \\
\hline Ji'nan & 0.7344 & 1 & 0.6493 & 2 & 0.7418 & 1 & 0.7050 & 2 & 0.7054 & 1 \\
\hline Zibo & 0.5348 & 4 & 0.4203 & 4 & 0.5507 & 2 & 0.3758 & 7 & 0.4607 & 4 \\
\hline Binzhou & 0.2090 & 6 & 0.1835 & 6 & 0.4370 & 6 & 0.3418 & 9 & 0.2922 & 8 \\
\hline Dongying & 0.2421 & 5 & 0.2426 & 5 & 0.4748 & 4 & 0.7154 & 1 & 0.4198 & 5 \\
\hline
\end{tabular}

\subsection{Evaluation and analysis of tourism development potential}

\subsubsection{Subsystem analysis of tourism development potential}

Tourism economic potential subsystem reflects the overall development level and status of regional tourism industry. It can be seen from table 2 that the highest development level of tourism economic potential is Ji'nan (0.7344), followed by Tai'an (0.6597), Jining (0.5783) and Zibo (0.5348), and the development level are all above 0.5. High quality tourism resources and high cultural value are one of the important reasons for Ji'nan, Tai'an, Jining and Zibo to attract tourists, thus promoting the development potential of local tourism economy. The tourism economic potential levels of Dongying (0.2421), Binzhou (0.2090), Heze $(0.1771)$ and Liaocheng (0.1429) are between 0.1 and 0.3 , and the tourism economic development potential is low. The tourism economic potential development level of Dezhou (0.0731) is the lowest, below 0.1. Dongying, Binzhou, Heze, Liaocheng and Dezhou have relatively low advantages in tourism resources and less tourism marketing, so the level of tourism economic development is relatively weak.

Tourism service potential subsystem reflects the regional tourism resource endowment and tourism service capacity. It can be seen from table 2 that the highest level of tourism service potential development is Jining (0.7285). Jining has excellent tourism resource endowment and rich cultural resources, so it has a high level of tourism service potential development. The second is Ji'nan (0.6493), Tai'an (0.5727) and Zibo (0.4203). The development level of tourism service potential is between 0.4 and 0.7. Due to rich tourism resources and historical and cultural resources, high service level of tourism facilities, and large number of tourist resorts and museums, the development level of tourism service potential of Ji'nan, Tai'an and Zibo is good. In addition, Dongying (0.2426), Binzhou (0.1835), Dezhou (0.1735), Liaocheng (0.1531) and Heze (0.1477) are relatively weak in tourism resource endowment ability, and the tourism service ability of travel agencies and star hotels is relatively low, so the development level of tourism service potential is low.

Tourism guarantee potential subsystem is the ability to guarantee the continuous development of regional tourism. It can be seen from table 2 that the highest development level of tourism guarantee potential is Ji'nan (0.7418) and Zibo (0.5507), and the development level are all above 0.5 . Due to the high level of economic development and the continuous improvement of economic structure, Ji'nan and Zibo have strong tourism guarantee ability and development potential. Tai'an (0.4809), Dongying (0.4748) and Liaocheng $(0.4542)$ are the second. The development level of tourism guarantee potential is between 0.45 and 0.5 . The overall development level is relatively balanced of these five cities, and they have a certain tourism guarantee potential. However, Binzhou (0.4370), Dezhou (0.4193), Heze (0.4110) and Jining (0.4086) had the lowest development level of tourism guarantee potential, lower than 0.45 . But on the whole, the overall level of tourism guarantee potential is better.

Tourism environmental potential subsystem is the basic guarantee for the healthy development of tourism. It can be seen from table 2 that the highest development level of tourism environmental potential is Dongying (0.7154) and Ji'nan (0.7050), and the development level are all above 0.7. Dongying City has a vast wetland area of the Yellow River Delta, the wetland area coverage rate is as high as $57.65 \%$, and the environmental quality is excellent; the treatment technology of waste water and waste gas in Ji'nan City is gradually improved, and the tourism environmental conditions are better. The second is Tai'an (0.5973), Jining (0.5772), Liaocheng (0.5000), Heze (0.4213), Zibo (0.3758), Dezhou (0.3472) and Binzhou(0.3418). The forest coverage rate and wetland coverage rate are better, but the comprehensive score of tourism environmental potential is the lowest due to the high discharge of pollutants such as wastewater, sulfur dioxide and industrial dust.

\subsubsection{Comprehensive analysis of tourism development potential}

Based on the four subsystems of tourism economic potential, tourism service potential, tourism guarantee potential and tourism environment potential, this paper comprehensively estimates and evaluates the tourism development potential of Shandong section of the Yellow 
River Basin. It can be seen from table 2 that the comprehensive development level of tourism development potential of the nine cities in the study area in 2019 is between 0.2734 and 0.7054 . The tourism development potential of the study area is at the medium level, and the development level of the region is unbalanced. Based on the natural fault method of Arc GIS 10.6, the comprehensive level of tourism development potential of nine cities in study area is divided into five levels, as shown in Figure 1.

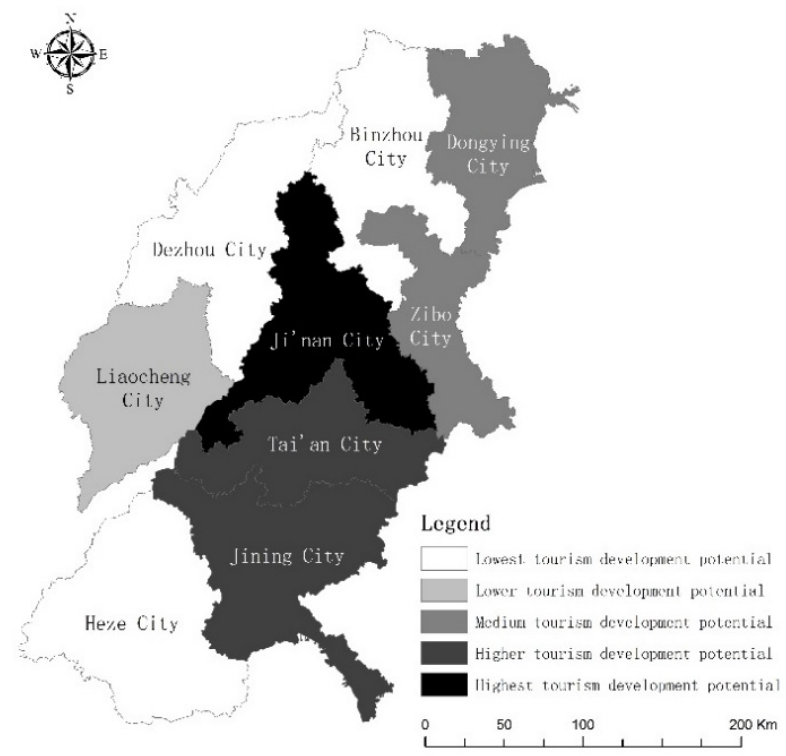

Fig 1. Tourism development potential of nine cities in Shandong section of the Yellow River Basin in 2019

Grade I was Ji'nan (0.7054). Ji'nan has a high level of development in economy, society, tourism and other aspects, with strong tourism service ability and guarantee ability. The driving effect of tourism economy is obvious, so the comprehensive level of tourism development potential is the highest.

Grade II were Jining (0.5832) and Tai'an (0.5804). Jining and Tai'an have higher tourism economic potential and tourism service potential, better tourism resource endowment and excellent tourism environment quality. Therefore, the comprehensive level of tourism development potential of Jining and Tai'an is higher.

Grade III were Zibo (0.4607) and Dongying (0.4198). Zibo has a good level of social and economic development and great potential for tourism protection. Dongying's tourism environmental potential ranks first among the nine cities, with rich wetland resources, good biodiversity and good tourism protection potential. Therefore, the comprehensive evaluation level of tourism development potential of Zibo and Dongying is better.

Grade IV was Liaocheng (0.3430). Liaocheng's economic level and tourism environment quality are good, but the tourism resource endowment is general, tourism economy driving ability is weak, tourism service ability is relatively poor, so the comprehensive score of tourism development potential is low.

Grade V were Heze (0.3028), Binzhou (0.2922) and Dezhou (0.2734). Due to the lack of characteristic tourism resources, strong economic security and high-quality tourism environment, the overall development level of tourism service potential, tourism security potential and tourism environment potential subsystem is relatively backward, which leads to the poor comprehensive level of tourism development potential.

\section{Countermeasures for high-quality tourism development in Shandong section of the Yellow River Basin}

\subsection{Strengthening regional tourism cooperation}

Since the national strategy of the Yellow River Basin was put forward, it has become an inevitable requirement to strengthen regional cooperation and promote coordinated development. The nine cities in the study area have some similarities in natural conditions and social and historical conditions. At the same time, under the leadership of Shandong Province, the economic policies and tourism development policies of the nine cities along the line have unified leadership. However, due to the restrictions of administrative divisions, there are differences and even imbalances in the development of tourism in each city. Therefore, under the background of high-quality development of the Yellow River Basin, the nine cities should thoroughly implement the basic requirements of strengthening regional cooperation, improve the inter regional cooperation mechanism, and strengthen regional communication, exchange and cooperation in the integration of tourism resources, development of tourism routes, tourism marketing, and tourism environmental protection. In addition, we should give full play to the resource advantages and characteristics of each city, integrate regional tourism resources, jointly build excellent tourism routes along the Yellow River Basin, form characteristic tourism products and tourism brands, and jointly promote the high-quality development of tourism.

\subsection{Promote the integration and development of regional culture and tourism}

In recent years, cultural tourism integration has gradually become the mainstream trend of tourism development. The Yellow River inherits thousands of years of Chinese historical civilization and contains profound historical and cultural heritage. Protecting, inheriting and carrying forward the Yellow River culture is one of the main objectives of ecological protection and high-quality development in the Yellow River Basin [1]. The nine cities in study area should take the Yellow River as the breakthrough point, deeply excavate the cultural connotation, study and design cultural tourism routes and cultural tourism brands, deepen the integration of culture and tourism from the development of cultural tourism resources, characteristic tourism, tourism cultural creation, tourism performance and other aspects, and cultivate and develop new forms of cultural tourism. At the same time, we should protect and inherit the intangible cultural heritage along the Yellow River, give full play to the 
advantages of local resources, fully show the confidence of cultural tourism resources, form high-quality cultural tourism routes, and promote the in-depth integration and high-quality development of culture and tourism.

\subsection{Improving regional tourism ecological environment}

To promote the high-quality development of economy and tourism in the Yellow River Basin, the first thing is to ensure the high-quality development of ecological environment. All along, due to the complexity and particularity of the Yellow River Basin, the ecological protection and management of the basin is a long-term and arduous task. The ecological problems of the upper, middle and lower reaches of the Yellow River are different, so the focus of ecological management is also different. The Shandong section of the Yellow River Basin is located in the Yellow River Delta, with a vast wetland area. The ecological environment of the Yellow River Delta should be mainly protected and biodiversity should be improved. In addition, we should strengthen ecological and environmental monitoring along the river basin, and continue to promote ecological protection, afforestation, and soil and water conservation along the river basin. Determine the tourist carrying capacity of the tourism areas, and carry out tourism activities within a reasonable carrying range. Gradually improve the tourism ecological environment and further promote the high-quality development of ecology and tourism.

\section{Conclusion}

Taking the high-quality development of the Yellow River Basin as the research background, this paper constructs the evaluation index system of tourism development potential which include tourism economic potential, tourism service potential, tourism guarantee potential and tourism environment potential, and calculates, evaluates and analyzes the tourism development potential of nine cities in study area in 2019. The results show that the development level of each city evaluated by different evaluation subsystems is quite different, and there is obvious imbalance. Finally, according to the evaluation results of tourism development potential, combined with the research background of high-quality development of the Yellow River Basin, this paper puts forward some countermeasures and suggestions for the high-quality development of tourism, so as to jointly promote the highquality development of economy, ecology and tourism in the Shandong section of the Yellow River Basin.

\section{Acknowledgements}

The authors express their gratitude to the referees for their valuable comments and their helps on how to improve the quality of our paper.

\section{Reference}

1. Xi Jinping. (2019) Speech at the Symposium on ecological protection and high quality development in the Yellow River River Basin [J]. China water conservancy, 20: 1-3.

2. Du Yan. (2014) Measurement and evaluation of tourism industry development potential: a case study of Hunan Province [J]. Economic geography,34: 176181.

3. Kelly M. (1998) Jordans potential tourism development[J]. Annals of Tourism Research, 25:904-918.

4. Roki Iwahashi. (2006) A theoretieal assessment of regional development effects on the demand forgeneral edueation $[\mathrm{J}]$. Eeonomies of Education Review. 2:387-394.

5. Taylor T K, Banda-Thole C. (2013) Tourism Development Potential of the Northern Province of Zambia[J]. American Journal of Tourism Management, 2:10-25.

6. Erdem H. (2015) Added Value of Health Tourism and its Potential in Bursa[J]. Russian Academic Journal, 31,136-140.

7. Cao Xinxiang. (2007) Comparative study on the development potential of China's provincial tourism [J]. Human geography,01: 18-22.

8. Weng gangmin, Ning Nan. (2015) Evaluation and Application Research on development potential of online tourism in China [J]. Business research,01: 175-179.

9. Wang guanxiao, Liang Liuke. (2015) Evaluation of urban tourism development potential in Shanxi Province $[\mathrm{J}]$. Resources and environment in arid areas, 29: 203-208.

10. Shi Dan, Yang Hui. (2019) Evaluation and Empirical Study on ecotourism development potential based on multilevel grey method [J]. Agricultural resources and Regionalization in China, 40: 40-48.

11. Shi Yuqing, Zhong Linsheng, Chen Tian. (2014) Evaluation of tourism competitiveness of China's land border counties [J]. Resources science, 36: 1133-1141.

12. Long Zhi, Zeng Shaolun. (2020) Tourism development quality evaluation and high-quality development path empirical research from the perspective of ecological civilization [J]. Ecological economy, 36: 122-128+162.

13. Xiang Yuchuan, Yang Xiaoxia. (2018) Evaluation of tourism development potential of ethnic minority areas in Southeast Chongqing Based on TOPSIS method [J]. Journal of Southwest Normal University (NATURAL SCIENCE EDITION), 43:67-74.

14. Du Ting, Xie Xianjian, Liang Haiyan, Huang an, Han Quanfang. (2014) Comprehensive evaluation and spatial analysis of county economy in Chongqing Based on Entropy TOPSIS and GIS [J]. Economic geography, 34: 40-47.

15. Lei xunping, Qiu Guanghua. (2016) Empirical Study 
on regional resources and environment carrying capacity evaluation based on Entropy TOPSIS Model [J]. Journal of environmental science, 36: 314-323. 